\title{
Minimal Residual Disease in Acute Lymphoblastic Leukemia
}

\author{
Pratik P. Patil ${ }^{1} \quad$ Esha Jafa² Mayank Aggarwal ${ }^{1}$ \\ ${ }^{1}$ Department of Medical Oncology, Max Super Speciality Hospital, \\ New Delhi, India \\ ${ }^{2}$ Department of Medical Oncology, Super Speciality Cancer \\ Institute, Lucknow, Uttar Pradesh, India
}

Ind J Med Paediatr Oncol 2021;42:71-76.

Acute lymphoblastic leukemia (ALL) is the most common malignancy in children accounting for 25 and $75 \%$ of childhood cancers and leukemia, respectively, citied as the major success stories in the world of oncology where the cure rates have gone up to $80 \%$ (event-free survival [EFS]) from literally zero in the 1950 s. $^{1-3}$ Prognostic factors play an important role in the strategic standard management of ALL wherein minimal residual disease (MRD) is now widely regarded as a clinically significant tool. A meta-analysis has proven that MRD negativity is directly proportional to the powerful predictors of disease-free survival (DFS) (hazard ratio [HR]: 0.23, [95\% Bayesian credible interval [BCI]: 0.18-0.28] for pediatric patients and 0.28 [95\% $\mathrm{BCI}$ : $0.24-0.33$ ] for adults) and overall survival (OS) (HR: 0.28, [95\% BCI: 0.19-0.41] and 0.28 [95\% BCI: 0.20-0.39] for children and adults with ALL, respectively). ${ }^{4}$

It now provides information depending on when the MRD assessment was performed: after induction therapy, after consolidation therapy (CT), or before and after stem cell transplant (SCT) and genomic information for targetable therapies available today, as shown in - Table 1. As of today, for the management of ALL, induction therapy to aim complete hematological recovery and complete remission (CR), followed by $\mathrm{CT}$ after attainment of $\mathrm{CR}$, with standard central nervous system (CNS) prophylaxis, is imperative. It is followed by SCT in few subsets. Mostly all pediatric and adult ALL guidelines have introduced informative checkpoints during the management of ALL. For pediatric subgroup, MRD negativity on day 15 of induction chemotherapy defines excellent outcomes, wherein in adults, MRD is taken later in the course at 4 weeks of starting induction chemotherapy and defines better survival rates. ${ }^{5,6}$

\begin{abstract}
Address for correspondence Pratik P Patil, MBBS MD (medicine) DNB (Medical Oncology), Department of Medical Oncology, Max Super Speciality Hospital, Shalimar Bagh, New Delhi 110088, India (e-mail: pratikpatil79@rediffmail.com).
\end{abstract}

\section{Molecular Detection Methods for Minimal Residual Disease}

Molecular detection methods for MRD identify cells either through patterns of phenotypic markers or differential gene expression through analysis by flow cytometry (FCM), polymerase chain reaction (PCR), or next-generation sequencing (NGS) (-Fig. 1).

An extensive marker screening panel of multiplex PCR assays targeting immunoglobulin/T-cell receptor (Ig/TR) gene rearrangements of a primary diagnosis sample is used to identify tumor-specific Ig/TR rearrangements. To discriminate malignant clonal rearrangements against a polyclonal background, PCR fragments from Ig/TR PCR assays are analyzed. The most frequently used methods for this fragment analysis are GeneScan or denaturing high pressure liquid chromatography, followed by heteroduplex analysis, which is comparable to multiplex PCR. ${ }^{7}$

\section{Sample Prerequisites}

Many large-scale studies have confirmed that the bone marrow sample is more informative than peripheral blood for the detection of MRD. . $^{8-10}$ There has been a difference of 1-3 log of MRD being lower in a paired peripheral blood than a bone marrow sample. ${ }^{11}$ Therefore, bone marrow assessments might be replaced by analysis of blood samples in T-ALL but not in BCP-ALL. The difference of residual tumor load is more apparent in B-ALL as compared with that of T-ALL. Bone marrow aspirate, however, remains the sample of choice for MRD detection. It is advisable that the first sample of aspirate should be used for MRD studies. Care should be taken not to dilute it with peripheral blood, and, usually, a $2 \mathrm{~mL}$,
DOI https://doi.org/ 10.1055/s-0041-1729730 ISSN 0971-5851
(C) 2021. Indian Society of Medical and Paediatric Oncology This is an open access article published by Thieme under the terms of the Creative Commons Attribution-NonDerivative-NonCommercial-License, permitting copying and reproduction so long as the original work is given appropriate credit. Contents may not be used for commercial purposes, or adapted, remixed, transformed or built upon. (https://creativecommons.org/licenses/by-nc-nd/4.0/). Thieme Medical and Scientific Publishers Pvt. Ltd. A-12, 2nd Floor, Sector 2, Noida-201301 UP, India 
Table 1 Genetic classification by prognosis of B-cell acute lymphoblastic leukemia

\begin{tabular}{|l|l|l|l|}
\hline Good prognosis & Intermediate prognosis & Poor prognosis & Undetermined prognosis \\
\hline Hyperdiploid karyotypes & $\mathrm{t}(1 ; 19) ;$ TCF3-PBX1 & Hypodiploid karyotypes & $\mathrm{t}(5 ; 14) ;$ IL3-IGH $^{\mathrm{a}}$ \\
\hline $\begin{array}{l}\mathrm{t}(12 ; 21) ; \text { ETV6-RUNX1 } \\
\text { (TEL-AML1) }\end{array}$ & & $\mathrm{t}(9 ; 22) ; \mathrm{BCR}-\mathrm{ABL}$ & \\
\hline & & Philadelphia-like ALL & \\
\hline & & $11 \mathrm{q} 23 \mathrm{MLL}$ arrangements & \\
\hline
\end{tabular}

Abbreviations: ALL, acute lymphoblastic leukemia; MLL, mixed-lineage leukemia.

at(5; 14); IL3-IGH is a World Health Organization-classified acute leukemia and prognosis data has not been determined.

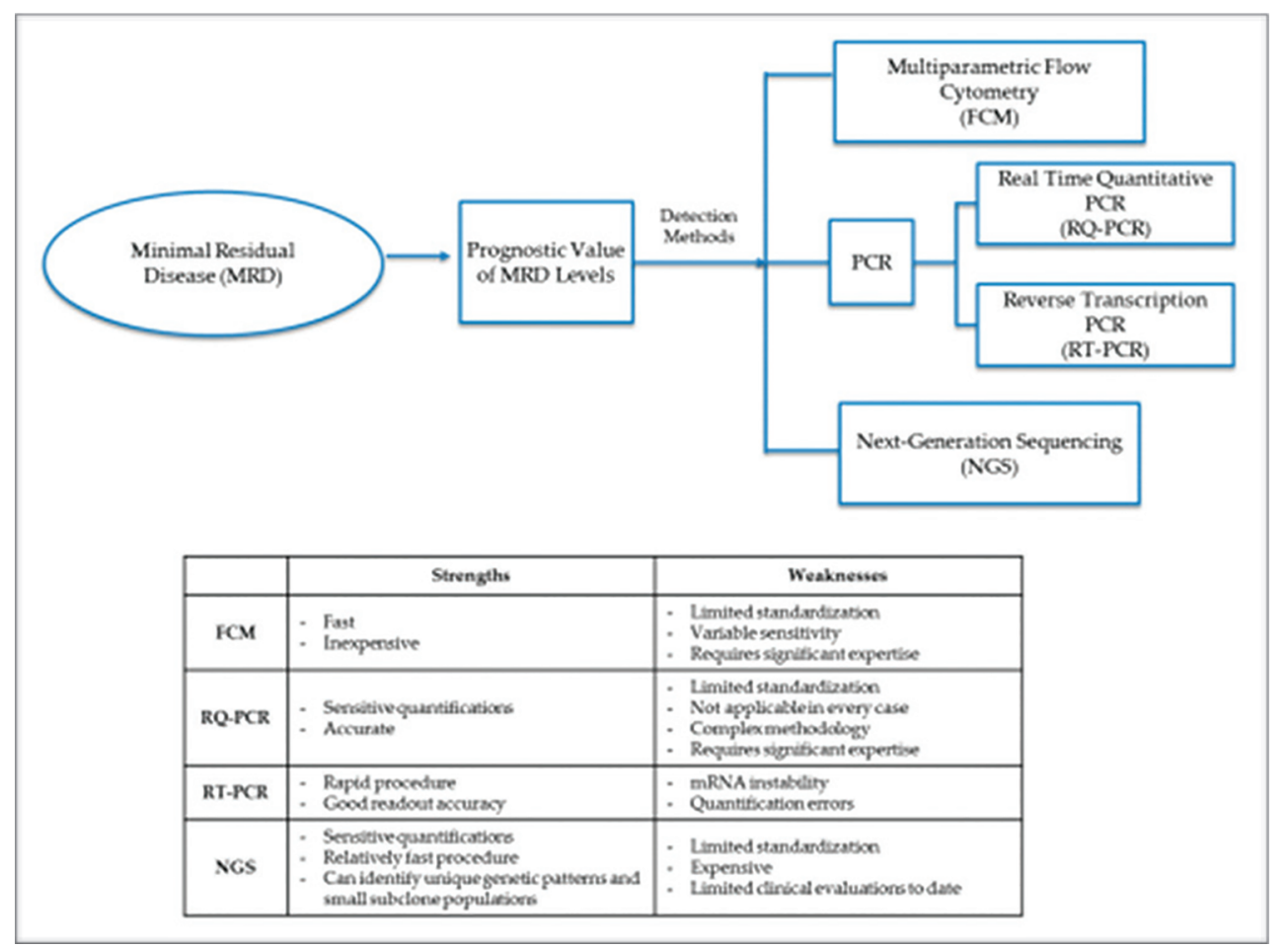

Fig.1 Detection methods for minimal residual disease. Methods to diagnose minimal residual disease either through phenotypic marker patterns or differential gene patterns through analysis by flow cytometry, polymerase chain reaction, real-time quantitative-polymerase chain reaction, reverse transcription-polymerase chain reaction, or next-generation sequencing.

but $<5 \mathrm{~mL}$, sample is sufficient to recover cells that give a sensitivity of B $10-4 .{ }^{12}$ Ethylenediaminetetraacetic acid or heparin-anticoagulated samples are good and preferably to be assayed for MRD detection within 24 to 48 hours.

\section{Minimal Residual Disease in Ph-Negative Acute Lymphoblastic Leukemia and Time Points}

MRD is a time point-dependent variable. MRD levels at different time points have different prognostic values for relapse: early MRD assessment at the end of induction or early consolidation identifies patients with a rapid tumor clearance and a very low risk of relapse representing a good prognosis, whereas any persisting MRD at the end of CT is associated with a particularly poor prognosis. The Programa para el Tratamiento de Hemopatias Malignas (PETHEMA) group evaluated the role of MRD (by FCM, cutoff: $5 \times 10^{-4}$ ) in 326 adult high-risk Philadelphia (Ph)-negative ALL patients and confirmed that the only prognostic factor was represented by MRD persistence after induction and early consolidation. ${ }^{13}$ Similarly, Group for Research on Adult Acute Lymphoblastic Leukemia (GRAALL) group in 955 patients assessing the role of SCT post-MRD after induction showed that the persistence is not abrogated by transplant procedures and that MRD-negative patients could be spared this approach. ${ }^{14}$ The Northern Italian Study Group with MRD post end of induction at week 4 and afterward 10, 16 , and 22 weeks to assess liposome-encapsulated cytarabine for CNS prophylaxis proved profound prognostic effect. The relapse risk (RR) was very low (17\% at 5 years) in the group of week 4 MRD responders and significantly lower (28\%) than that in nonresponders (57\%) when week 10 MRD results were examined. ${ }^{15}$ The German Multicenter Study Group for Adult ALL for Ph negative patients with SR/HR features (580 patients) in CR showed MRD after standard induction and consolidation treatment was the only significant prognostic factor for remission duration and survival in both risk groups, ${ }^{16}$ which has been confirmed later by many trials. ${ }^{13-15}$ 


\section{Minimal Residual Disease in Ph-Positive Acute Lymphoblastic Leukemia}

This subset of ALL, defined as a more high-risk group with $\mathrm{Ph}$ chromosome-forming breakpoint cluster regionAbelson gene (BCR/ABLl) rearrangement seen in 20 to $25 \%$ of ALL patients, is more common in adults than the pediatric population and increases in incidence with increasing age group. This subgroup was always defined as the highest risk group till tyrosine kinase inhibitors (TKIs) were brought into practice that revolutionized treatment till the present date where this Ph-positive ALL subset can attain CR in almost all cases with the TKIs such as imatinib, dasatinib, and ponatinib with or without chemotherapy as a therapeutic strategy, further improving EFS and also the OS with the number of $\mathrm{Ph}$-positive patients who could further receive SCT. ${ }^{17-21}$

Like in the Ph- subset where MRD reduction serves as a prognostic tool for improved EFS and OS, the Gruppo Italiano Malattie Ematologiche Maligne dell'Adulto (GIMEMA) trial proves again in the Ph-positive subset that MRD reduction correlates with the EFS and OS irrespective of the inhibitor used $^{22}$ and that a very early clearance has a better prognosis. ${ }^{23}$ Initially, all Ph-positive patients would be taken for SCT irrespective of the treatment used, but now, cases that are persistently MRD negative could avoid this and the debate continues. ${ }^{24,25}$ For therapeutic purposes too, MRD persistence or positivity or its reversal can signify the presence of a clone of mutation resistance, like T315-I that warrants novel TKIs (ponatinib) or combinations with TKI and monoclonal antibodies (blinatumomab).

Today, clinicians can vouch for more from MRD testing where more than one marker could be identified, like in pediatric ALL pH-positive subsets, $20 \%$ or more children could have significantly higher levels of $\mathrm{BCR} / \mathrm{ABLl}$, which is evaluated by estimating both DNA and RNA fusion levels shown by Hovorkova et al ${ }^{26}$ than Ig/TR/TKZF1 deletions, proving that $\mathrm{BCR} / \mathrm{ABL} 1$ signals could arise from different hematopoietic progenitors. Similarly, a trial by Cazzaniga et al proved that positive MRD reports by assessing Ig/TR deletion levels at after induction and consolidation are strongly prognosticative of relapse, ${ }^{27}$ wherein a formal correlation between Ig/TR and BCR/ABL1 proves again a similar conclusion for relapse with similarity of the technique used (69\%). In adult patients, a trial by Clappier et $\mathrm{a}^{28}$ found discordance in genomic and RNA-BCR/ABL1 levels because of p210 isoforms, Ikaros family zinc finger protein 1 (IKZF1) deletions, again proving that signals arise from different hematopoietic cells than lymphoblasts and represents an altogether different subset of "CML-like subtype"; however, there is no consensus as to which is suitable for treatment decisions.

\section{Ph-Like Acute Lymphoblastic Leukemia}

The rate of $\mathrm{CR} / \mathrm{CR}$ with incomplete platelet recovery (CRp) was similar in the three disease subgroups (Ph-like ALL, 89\%; Ph-positive ALL, 93\%; and B-other, 94\%; $p=0.57$ ). ${ }^{29}$ However, patients with Ph-like ALL were statistically significantly less likely to achieve MRD-remission as assessed by FCM (30\% for Ph-like ALL vs. $56 \%$ for Ph-positive ALL vs. $87 \%$ for B-other; $p$ $<0.001$ ), with achievement of MRD negativity at the time of remission having no impact on inferior long-term outcomes. In addition, there was no difference in the $\mathrm{CR} / \mathrm{CRp}$ rate and MRD remission rate between the Ph-like CRLF2-positive and Ph-like non-CRLF2 groups. Because the majority of patients with Ph-like ALL receive hyper-cyclophosphamide, vincristine, Adriamycin, and dexamethasone-based treatment, intensification of chemotherapy treatment is unlikely to benefit adult patients with Ph-like ALL. It remains to be determined whether addition of novel monoclonal antibodies (such as inotuzumab ozogamicin) or bispecific antibodies (such as blinatumomab) could improve the outcome of this group of patients. ${ }^{30}$

\section{Minimal Residual Disease and Stem Cell Transplantation}

SCT is a procedure still regarded as the one with high mortality and toxicity, which is performed for ALLS with MRD persistence/positivity and remains a major tool for decision-making, which could be seen in $20 \%$ of patients. ${ }^{31}$ Trials have proven the prognostic impact of MRD positive on SCT from time to time ${ }^{32,33}$ and also the relevance of performing MRD for pretransplant assessment. ${ }^{34-36}$ MRD levels of $>10^{3}$ at week $16 / 22$ post consolidation had worst prognosis and posttransplant mortality with 6-year RR of 64 vs. $23 \%$ for MRD $<10^{3}$ shown by Bassan et al. ${ }^{37}$ A meta-analysis on 21 reports including $>20,000$ patients has proven the same MRD positivity results in posttransplant mortality and reduced relapse-free survival, EFS, and OS. ${ }^{38}$ MRD positivity pretransplant could therapeutically benefit from immunotherapeutic compounds such as blinatumomab and inotuzumab and possibly chimeric antigen receptor (CAR)-T-cells in future too, aiming to obtain a MRD-negative status, and also help in identifying early molecular relapses when done at day 30 as it will help taper immunosuppression early or preemptively start TKIs in a Ph positive B-ALL.

MRD positivity posttransplant accounts for significantly worse outcomes as compared with their MRD-negative counterparts ${ }^{39}$ but is less commonly practiced as donor chimerism provides risk for early relapse. ${ }^{40}$

\section{Minimal Residual Disease and Novel Markers}

Extensive genetics and molecular markers of ALL mandate combining MRD with other markers, for example, in a 400 young adult cohort of Ph-negative ALL, the GRAAL group identified a high-risk relapsed population by MRD-del IKZF1 positive, absent NOTCH1/FBXW7 mutation, N/K-RAS mutation, and/or PTEN gene alteration in T-cell ALL positive. ${ }^{41}$ Similarly, in pediatric ALL, presence of IKZF1 intragenic deletion and P2RY8-CRLF2 provides additional prognostic information over MRD alone. ${ }^{42}$ 


\section{Minimal Residual Disease and Novel Agents}

Blinatumomab is a bispecific anti-CD19 and anti-CD3 construct, recruiting cytotoxic T-cells against CD19 positive blast T-cells, bridging malignant B-cells directly to $\mathrm{CD} 3$ positive T-cells, bypassing T-cell receptor specificity and major histocompatibility complex class 1 molecules, ${ }^{43,44}$ and inducing T-cell activation and release of inflammatory cytokines. ${ }^{45}$ It has been approved for refractory ALL and more recently for MRD positive patients (response rates of 43-69\%). ${ }^{46,47}$ Patients with MRD-status have demonstrated a longer median OS and median DFS compared to MRD-positive counterparts. ${ }^{48,49}$ In MRD-positive patients, blinatumomab induced a complete MRD response in 78\% of cases and as expected, MRD responders had a longer RFS than nonresponders. A small fraction of complete MRD responders did not undergo transplant and is still in continuous CR. . $^{50,51}$

Inotuzumab ozogamicin-an antibody drug conjugate of monoclonal antibody directed to CD22 and a cytotoxic agent-is approved as monotherapy of relapsed/refractory adult CD22-positive ALL patients. Patients treated with inotuzumab ozogamicin reached response rates ranging from 58 to $81 \%$, with 72 to $78 \%$ of these having MRD results below $0.01 \%{ }^{52,53}$ by FCM assessment. While this compound appears to be extremely effective in reinducing responses, it must be underlined that CR duration is usually short, and therefore SCT must be performed as soon as possible.

CAR-T-cells are patient-derived or, less frequently, donor-derived normal T-cells molecularly engineered to express a T-cell receptor-mediating cytotoxicity toward anti-CD19 (in most cases). After CAR-T-cells are infused into a patient, they act as a "living drug" against cancer cells: they bind to the target, become activated, proliferate, and exert their cytotoxic activity. Several groups have shown that most of the responding patients (both children and adults) become MRD negative (at least by FCM $)^{54,55}$ and maintain this status for several months or years. ${ }^{56,57}$ Data on the prognostic value of MRD in this setting are still preliminary. However, differently from first-line chemotherapeutic approaches, relapse is observed also in patients reaching an MRD negativity, mostly because of the loss of CD19. Therefore, MRD response in this setting seems to be an essential but not sufficient criterion for the definition of long-term remissions. Higher sensitivities or earlier MRD assessments might be necessary to identify a subgroup of patients with a particularly rapid and deep MRD response and a better prognosis.

\section{Conclusions}

MRD stands as an independent predictor of DFS and OS for both pediatric and adult patients of ALL during treatment, and also for pre- and post-SCT settings. Gene fusions and IG/TR gene molecular rearrangements are used as targets to identify residual leukemic cells in ALL with/without newer markers for therapeutic actionable purposes and to also improve the evaluable numbers. Multicolor FCM and real time quantitative-PCR are broad platforms for MRD assessment and monitoring provided limitations are overcome. PCR, NGS, and next-generation FCM, making them standard of care is yet to be proven that could be proven as an important way to identify MRD.

\section{Financial Support and Sponsorship}

Nil.

\section{Conflicts of Interest}

There are no conflicts of interest.

\section{Acknowledgment}

All contributors have equally participated and shared in terms of concepts, intellectual content, design, literature search, experimental studies, data acquisition, data analysis, statistical analysis, manuscript preparation, editing, and review.

\section{References}

1 Gaynon PS. Childhood acute lymphoblastic leukaemia and relapse. Br J Haematol 2005;131(5):579-587

2 Chessells JM, Hardisty RM, Richards S. Long survival in childhood lymphoblastic leukaemia. $\mathrm{Br} \mathrm{J}$ Cancer 1987;55(3):315-319

3 Shanta V, Maitreyan V, Sagar TG, Gajalakshmi CK, Rajalekshmy KR. Prognostic variables and survival in pediatric acute lymphoblastic leukemias: cancer institute experience. Pediatr Hematol Oncol 1996;13(3):205-216

4 Berry DA, Zhou S, Higley $\mathrm{H}$, et al. Association of minimal residual disease with clinical outcome in pediatric and adult acute lymphoblastic leukemia: a meta-analysis. JAMA Oncol 2017;3(7):e170580

5 Basso G, Veltroni M, Valsecchi MG, et al. Risk of relapse of childhood acute lymphoblastic leukemia is predicted by flow cytometric measurement of residual disease on day 15 bone marrow. J Clin Oncol 2009;27(31):5168-5174

6 Šálek C, Folber F, Froňková E, et al. Czech Leukemia Study Group - for Life. Early MRD response as a prognostic factor in adult patients with acute lymphoblastic leukemia. Eur J Haematol 2016;96(3):276-284

7 Trautmann H, Bautz J, Kruse AW, Kneba M, Brüggemann M. Molecular Characterization of Immune Gene Rearrangement Profiles in Acute Lymphoblastic Leukemia (ALL) using QIAxcel ${ }^{\circledR}$ Advanced Department of Internal Medicine II, Christian Albrechts University. Campus Kiel, Germany: University Medical Center Schleswig Holstein. Available from: https://www.qiagen.com/us/resources/download.aspx?id= 8878bf26-9da2-435c-9160-551fbc5351b7\&lang=en. Accessed April 13, 2021

8 Coustan-Smith E, Sancho J, Hancock ML, et al. Use of peripheral blood instead of bone marrow to monitor residual disease in children with acute lymphoblastic leukemia. Blood 2002;100(7):2399-2402

9 Brisco MJ, Sykes PJ, Hughes E, et al. Monitoring minimal residual disease in peripheral blood in B-lineage acute lymphoblastic leukaemia. Br J Haematol 1997;99(2):314-319

10 van der Velden VH, Jacobs DC, Wijkhuijs AJ, et al. Minimal residual disease levels in bone marrow and peripheral blood are comparable in children with $\mathrm{T}$ cell acute lymphoblastic leukemia (ALL), but not in precursor-B-ALL. Leukemia 2002;16(8):1432-1436

11 van Dongen JJ, Seriu T, Panzer-Grümayer ER, et al. Prognostic value of minimal residual disease in acute lymphoblastic leukaemia in childhood. Lancet 1998;352(9142):1731-1738 
12 van Dongen JJ, van der Velden VH, Brüggemann M, Orfao A. Minimal residual disease diagnostics in acute lymphoblastic leukemia: need for sensitive, fast, and standardized technologies. Blood 2015;125(26):3996-4009

13 Ribera JM, Oriol A, Morgades M, et al. Treatment of high-risk Philadelphia chromosome-negative acute lymphoblastic leukemia in adolescents and adults according to early cytologic response and minimal residual disease after consolidation assessed by flow cytometry: final results of the PETHEMA ALL-AR-03 trial. J Clin Oncol 2014;32(15):1595-1604

14 Dhédin N, Huynh A, Maury S, et al. GRAALL group. Role of allogeneic stem cell transplantation in adult patients with Ph-negative acute lymphoblastic leukemia. Blood 2015;125(16):2486-2496, quiz 2586

15 Bassan R, Masciulli A, Intermesoli T, et al. Final results of Northern Italy Leukemia Group (NILG) trial 10/07 combining pediatric-type therapy with minimal residual disease study and risk-oriented hematopoietic cell transplantation in adult acute lymphoblastic leukemia (ALL) Blood 2016;128:176

16 Gökbuget N, Kneba M, Raff T, et al; German Multicenter Study Group for Adult Acute Lymphoblastic Leukemia. Adult patients with acute lymphoblastic leukemia and molecular failure display a poor prognosis and are candidates for stem cell transplantation and targeted therapies. Blood 2012;120(9):1868-1876

17 Chalandon Y, Thomas X, Hayette S, et al. Group for Research on Adult Acute Lymphoblastic Leukemia (GRAALL). Randomized study of reduced-intensity chemotherapy combined with imatinib in adults with Ph-positive acute lymphoblastic leukemia. Blood 2015;125(24):3711-3719

18 Foà R, Vitale A, Vignetti M, et al. GIMEMA Acute Leukemia Working Party. Dasatinib as first-line treatment for adult patients with Philadelphia chromosome-positive acute lymphoblastic leukemia. Blood 2011;118(25):6521-6528

19 Yoon JH, Yhim HY, Kwak JY, et al. Minimal residual disease-based effect and long-term outcome of first-line dasatinib combined with chemotherapy for adult Philadelphia chromosome-positive acute lymphoblastic leukemia. Ann Oncol 2016;27(6):1081-1088

20 Maino E, Sancetta R, Viero P, et al. Current and future management of Ph/BCR-ABL positive ALL. Expert Rev Anticancer Ther 2014; 14(6):723-740

21 Pfeifer H, Wassmann B, Bethge W, et al. GMALL Study Group. Randomized comparison of prophylactic and minimal residual disease-triggered imatinib after allogeneic stem cell transplantation for BCR-ABL1-positive acute lymphoblastic leukemia. Leukemia 2013;27(6):1254-1262

22 Chiaretti S, Vitale A, Vignetti M, et al. A sequential approach with imatinib, chemotherapy and transplant for adult $\mathrm{Ph}+$ acute lymphoblastic leukemia: final results of the GIMEMA LAL 0904 study. Haematologica 2016;101(12):1544-1552

23 Lee S, Kim DW, Cho BS, et al. Impact of minimal residual disease kinetics during imatinib-based treatment on transplantation outcome in Philadelphia chromosome-positive acute lymphoblastic leukemia. Leukemia 2012;26(11):2367-2374

24 Lussana F, Intermesoli T, Gianni F, et al. Achieving molecular remission before allogeneic stem cell transplantation in adult patients with Philadelphia chromosome-positive acute lymphoblastic leukemia: impact on relapse and long-term outcome. Biol Blood Marrow Transplant 2016;22(11):1983-1987

25 Nishiwaki S, Imai K, Mizuta S, et al. Impact of MRD and TKI on allogeneic hematopoietic cell transplantation for Ph+ALL: a study from the adult ALL WG of the JSHCT. Bone Marrow Transplant 2016;51(1):43-50

26 Hovorkova L, Zaliova M, Venn NC, et al. Monitoring of childhood ALL using BCR-ABL1 genomic breakpoints identifies a subgroup with CML-like biology. Blood 2017;129(20):2771-2781
27 Cazzaniga G, De Lorenzo P, Alten J, et al. Predictive value of minimal residual disease in Philadelphia-chromosomepositive acute lymphoblastic leukemia treated with imatinib in the European intergroup study of post-induction treatment of Philadelphia-chromosome-positive acute lymphoblastic leukemia, based on immunoglobulin/T-cell receptor and BCR/ ABL1 methodologies. Haematologica 2018;103(1):107-115

28 Clappier E, Kim R, Cayuela JM, et al. Persistent BCR-ABL1 Clonal Hematopoiesis after Blast Clearance Identifies a CMLLike Subgroup of Patients with Philadelphia Chromosomepositive (Ph+) ALL: Interim Results from GRAAPH-2014 Trial. Stockholm: 23th EHA Annual Congress Stockholm; 2018. p. S1568

29 Huguet F, Leguay T, Raffoux E, et al. Pediatric-inspired therapy in adults with Philadelphia chromosome-negative acute lymphoblastic leukemia: the GRAALL-2003 study. J Clin Oncol 2009;27(6):911-918

30 Jain N, Roberts KG, Jabbour E, et al. Ph-like acute lymphoblastic leukemia: a high-risk subtype in adults. Blood 2017;129(5):572-581

31 Buckley SA, Appelbaum FR, Walter RB. Prognostic and therapeutic implications of minimal residual disease at the time of transplantation in acute leukemia. Bone Marrow Transplant 2013;48(5):630-641

32 Campana D, Leung W. Clinical significance of minimal residual disease in patients with acute leukaemia undergoing haematopoietic stem cell transplantation. $\mathrm{Br} \mathrm{J}$ Haematol 2013;162(2):147-161

33 Bassan R, Spinelli O, Oldani E, et al. Different molecular levels of post-induction minimal residual disease may predict hematopoietic stem cell transplantation outcome in adult Philadelphia-negative acute lymphoblastic leukemia. Blood Cancer J 2014;4:e225

34 Hoelzer D. Personalized medicine in adult acute lymphoblastic leukemia. Haematologica 2015;100(7):855-858

35 Zhou Y, Slack R, Jorgensen JL, et al. The effect of peritransplant minimal residual disease in adults with acute lymphoblastic leukemia undergoing allogeneic hematopoietic stem cell transplantation. Clin Lymphoma Myeloma Leuk 2014;14(4):319-326

36 Shen Z, Gu X, Mao W, et al. Influence of pre-transplant minimal residual disease on prognosis after Allo-SCT for patients with acute lymphoblastic leukemia: systematic review and meta-analysis. BMC Cancer 2018;18(1):755

37 Bar M, Wood BL, Radich JP, et al. Impact of minimal residual disease, detected by flow cytometry, on outcome of myeloablative hematopoietic cell transplantation for acute lymphoblastic leukemia. Leukemia Res Treat 2014;2014:421723

38 Terwey TH, Hemmati PG, Nagy M, et al. Comparison of chimerism and minimal residual disease monitoring for relapse prediction after allogeneic stem cell transplantation for adult acute lymphoblastic leukemia. Biol Blood Marrow Transplant 2014;20(10):1522-1529

39 Eckert C, Flohr T, Koehler R, et al. Very early/early relapses of acute lymphoblastic leukemia show unexpected changes of clonal markers and high heterogeneity in response to initial and relapse treatment. Leukemia 2011;25(8):1305-1313

40 Szczepanski T, van der Velden VH, Waanders E, et al. Late recurrence of childhood T-cell acute lymphoblastic leukemia frequently represents a second leukemia rather than a relapse: first evidence for genetic predisposition. J Clin Oncol 2011;29(12):1643-1649

41 Beldjord K, Chevret S, Asnafi V, et al. Group for Research on Adult Acute Lymphoblastic Leukemia (GRAALL). Oncogenetics and minimal residual disease are independent outcome predictors in adult patients with acute lymphoblastic leukemia. Blood 2014;123(24):3739-3749 
42 Sutton R, Venn NC, Law T, et al. A risk score including microdeletions improves relapse prediction for standard and medium risk precursor B-cell acute lymphoblastic leukaemia in children. Br J Haematol 2018;180(4):550-562

43 Löffler A, Gruen M, Wuchter C, et al. Efficient elimination of chronic lymphocytic leukaemia B cells by autologous $\mathrm{T}$ cells with a bispecific anti-CD19/anti-CD3 single-chain antibody construct. Leukemia 2003;17(5):900-909

44 Leone P, Shin EC, Perosa F, Vacca A, Dammacco F, Racanelli V. MHC class I antigen processing and presenting machinery: organization, function, and defects in tumor cells. J Natl Cancer Inst 2013;105(16):1172-1187

45 Brandl C, Haas C, d'Argouges S, et al. The effect of dexamethasone on polyclonal $\mathrm{T}$ cell activation and redirected target cell lysis as induced by a CD19/CD3-bispecific single-chain antibody construct. Cancer Immunol Immunother 2007;56(10):1551-1563

46 Topp MS, Gökbuget N, Zugmaier G, et al. Phase II trial of the anti-CD19 bispecific $\mathrm{T}$ cell-engager blinatumomab shows hematologic and molecular remissions in patients with relapsed or refractory B-precursor acute lymphoblastic leukemia. J Clin Oncol 2014;32(36):4134-4140

47 Topp MS, Gökbuget N, Stein AS, et al. Safety and activity of blinatumomab for adult patients with relapsed or refractory B-precursor acute lymphoblastic leukaemia: a multicentre, single-arm, phase 2 study. Lancet Oncol 2015;16(1):57-66

48 Kantarjian H, Stein A, Gökbuget N, et al. Blinatumomab versus chemotherapy for advanced acute lymphoblastic leukemia. $\mathrm{N}$ Engl J Med 2017;376(9):836-847

49 Zugmaier G, Gökbuget N, Klinger M, et al. Long-term survival and T-cell kinetics in relapsed/refractory ALL patients who achieved MRD response after blinatumomab treatment. Blood 2015;126(24):2578-2584

50 Gökbuget N, Zugmaier G, Klinger M, et al. Long-term relapsefree survival in a phase 2 study of blinatumomab for the treatment of patients with minimal residual disease in B-lineage acute lymphoblastic leukemia. Haematologica 2017;102(4):e132-e135

51 Gökbuget N, Dombret H, Bonifacio M, et al. Blinatumomab for minimal residual disease in adults with B-cell precursor acute lymphoblastic leukemia. Blood 2018;131(14):1522-1531

52 Kantarjian H, Thomas D, Jorgensen J, et al. Results of inotuzumab ozogamicin, a CD22 monoclonal antibody, in refractory and relapsed acute lymphocytic leukemia. Cancer 2013;119(15):2728-2736

53 Kantarjian HM, DeAngelo DJ, Stelljes M, et al. Inotuzumab ozogamicin versus standard therapy for acute lymphoblastic leukemia. N Engl J Med 2016;375(8):740-753

54 Davila ML, Riviere I, Wang X, et al. Efficacy and toxicity management of 19-28z CAR T cell therapy in B cell acute lymphoblastic leukemia. Sci Transl Med 2014;6(224):224ra25

55 Lee DW, Kochenderfer JN, Stetler-Stevenson M, et al. T cells expressing CD19 chimeric antigen receptors for acute lymphoblastic leukaemia in children and young adults: a phase 1 dose-escalation trial. Lancet 2015;385(9967):517-528

56 Gardner RA, Finney O, Annesley C, et al. Intent-to-treat leukemia remission by CD19 CAR $T$ cells of defined formulation and dose in children and young adults. Blood 2017;129(25):3322-3331

57 Brentjens RJ, Davila ML, Riviere I, et al. CD19-targeted T cells rapidly induce molecular remissions in adults with chemotherapy-refractory acute lymphoblastic leukemia. Sci Transl Med 2013;5(177):177ra38 